\title{
Generic Models of Wind Turbine Generators for Advanced Applications in a VSC-based Offshore HVDC Network
}

Zeni, Lorenzo; Margaris, loannis; Hansen, Anca Daniela; Sørensen, Poul Ejnar; Kjær, P.C.

Published in:

Proceedings of the 10th IET International Conference on AC and DC Power Transmission (ACDC 2012)

Link to article, DOI:

10.1049/cp.2012.1980

Publication date:

2012

Document Version

Peer reviewed version

Link back to DTU Orbit

Citation (APA):

Zeni, L., Margaris, I., Hansen, A. D., Sørensen, P. E., \& Kjær, P. C. (2012). Generic Models of Wind Turbine Generators for Advanced Applications in a VSC-based Offshore HVDC Network. In Proceedings of the 10th IET International Conference on AC and DC Power Transmission (ACDC 2012) Institution of Engineering and Technology. https://doi.org/10.1049/cp.2012.1980

\section{General rights}

Copyright and moral rights for the publications made accessible in the public portal are retained by the authors and/or other copyright owners and it is a condition of accessing publications that users recognise and abide by the legal requirements associated with these rights.

- Users may download and print one copy of any publication from the public portal for the purpose of private study or research.

- You may not further distribute the material or use it for any profit-making activity or commercial gain

- You may freely distribute the URL identifying the publication in the public portal 


\title{
Generic Models of Wind Turbine Generators for Advanced Applications in a VSC-based Offshore HVDC Network
}

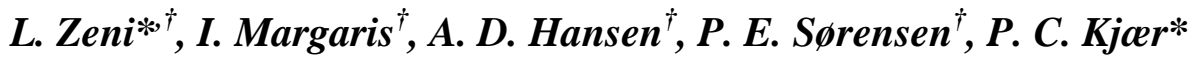 \\ *Vestas Wind Systems, Denmark - lozen@vestas.com, ${ }^{\dagger} D T U$ Wind Energy,Denmark-iomar@dtu.dk
}

Keywords: VSC-HVDC, modelling, integration of wind power, frequency control

\begin{abstract}
This paper focuses on generic Type 4 wind turbine generators models, their applicability in modern HVDC connections and their capability to provide advanced ancillary services therefrom. A point-to-point HVDC offshore connection is considered. Issues concerning coordinated HVDC and wind farm control as well as the need of a communication link are discussed. Two possible control configurations are presented and compared. The first is based on a communication link transmitting the onshore frequency directly to the wind power plant, while the second makes use of a coordinated control scheme involving the HVDC converters- The performance against frequency disturbances of the two presented configurations is assessed and discussed by means of simulations.
\end{abstract}

\section{Introduction}

Historically, wind power has been easily accommodated by power systems, despite its volatility and partial unpredictability. However, power systems facing a very large penetration of renewable energy are now challenged [1] and start calling for the provision of ancillary services from wind turbines (WTs) and wind power plants (WPPs). Starting from low voltage ride through (LVRT) and simple frequency control, other advanced ancillary services may be required to future WPPs $[2,3,4]$. Among those, one could mention for example inertial response [5], synchronising torque and power system stabilisation.

On the other hand, plans already exist regarding the massive installation of offshore wind power and high voltage direct current (HVDC) interconnectors in the North Sea [6,7]. Should such plans materialise, as a consequence of the significant distance from shore a large part of the capacity will most likely be connected to shore through HVDC technology based on voltage source converters (VSCs), due to several reasons, among which are e.g. longer possible transmission distance through undersea cables, better controllability, black-start capability, compactness, etc. compared to classical line commutated (LCC) topologies [8].

Generic WT and WPP models exist and are commonly used in power system studies $[5,9,10]$. It is hence interesting to assess their validity and capability of providing inertial response, synchronising torque and power system stabilisation even when employed in VSC-HVDC interconnections. Secondly, control solutions solely based on communication should be compared to possible coordinated communication-less control schemes which allow for the achievement of the same targets [11]. The first step in a complete comparison between such different control layouts can be the analysis of a point-to-point (P2P) link followed by the extension to more complex multi-terminal (MT) HVDC grids.

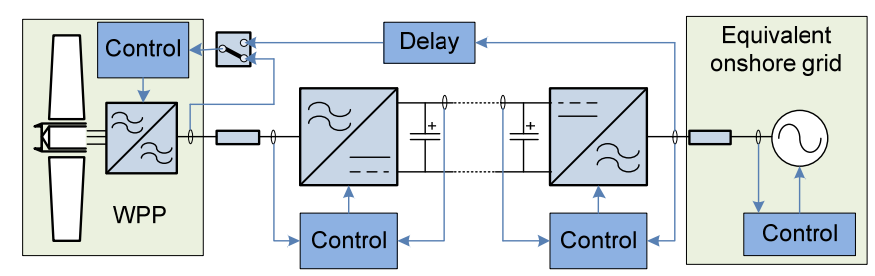

Figure 1: Simplified circuit diagram of P2P HDVC connected WPP.

This paper thus focuses on a P2P HVDC connection of a WPP, relying on the simplified circuit sketched in Figure 1, demonstrating the validity of generic WT models and proposing a first comparison between communication-based frequency control (hereafter referred to as Option A) and coordinated frequency control (hereafter Option B). The former is based on transmission of the onshore frequency value to the WPP via e.g. optical fibre, whilst the latter aims at mirroring the onshore frequency variations onto the offshore grid through appropriate control blocks [11]. Only frequency droop and inertial contribution are of concern in this work.

A brief description of the simulation model is provided in Section 2, while the results are shown and discussed in Section 3. Conclusive remarks are reported in Section 4, where the track for future work is also proposed.

\section{Model description}

Root mean square (RMS) models for WPP and HVDC converters have been used for the investigation and implemented in DIgSILENT PowerFactory. A brief description of the simulation model for WPP and HVDC interconnection is given below. 


\subsection{Wind turbine}

The Type 4 wind turbine model used in this investigation follows the basic structure of the Type 4 standard wind turbine model proposed by the IEC Committee in the IEC 61400-27-1 [12], nevertheless includes additional features in order to address frequency control issues. It is worth noting that the standard models for wind turbines [12] are suitable for fundamental frequency positive sequence response simulations during short term events in the power system, such as voltage dips. The response of the Type 4 standard model during voltage dips in a power system is for example extensively described in [13].

The standard models for wind turbines, described in [12], are not able to represent frequency control capabilities. They are not intended for studies with wind speed variability as well as not for studies where information on the available power is primordial in reflecting the limits in providing ancillary services, i.e. inertia control, by the wind power plants in specific situations. The Type 4 wind turbine model used in this work includes therefore several adjustments and extensions of the standard models presented in [12], in order to represent the capability of wind turbines to provide active power during events in the power system that affect frequency.

The extended and adjusted configuration of the standard Type 4 wind turbine model, used in this work, is illustrated in Figure 2. It consists mainly of an aerodynamic model, a pitch control, a mechanical model, a generator system (modelled via a static generator), an electrical control system and a protection system. Besides the electrical control system, which includes the active and reactive power control loops, there is also a maximum power point tracking (MPPT) control and a frequency control, which generate the power reference signal for the electrical control.

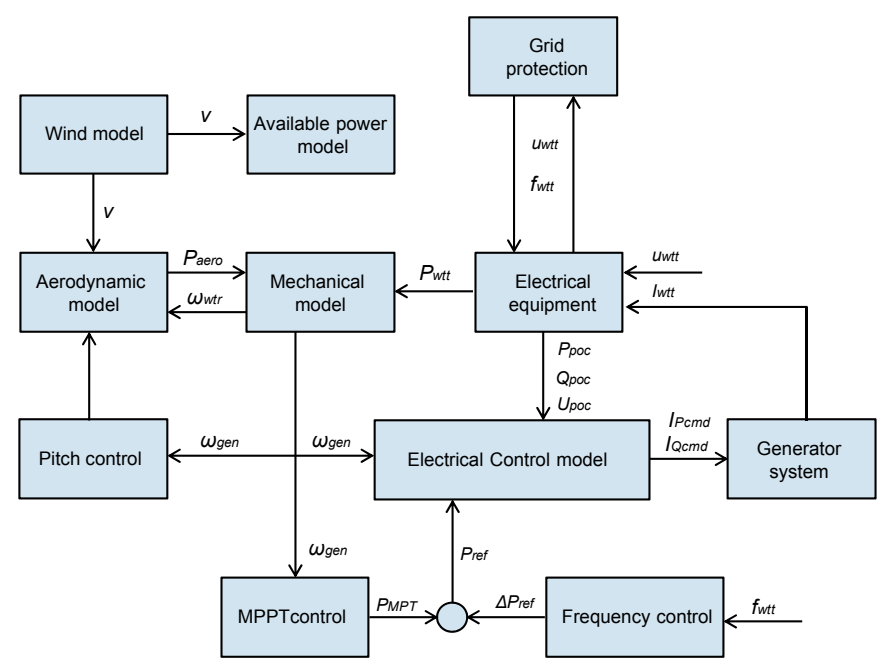

Figure 2: Wind turbine model and control.

An adequate complex mechanical model, i.e. a 2-mass model similar to that existing in the standard model, is also of great significance for frequency control studies, as it might reflect some limits regarding the possibilities of the wind turbines to provide active power during frequency events. In addition to the standard model, the present model contains an aerodynamic model and thus also a pitch control model, as the coupling between the mechanical model and the aerodynamic model is essential for the dynamics of the rotor speed, which might reflect the limits for inertia control contribution of the wind turbine.

The wind farm model, used in the present investigation, is an aggregated wind turbine model. The aggregation method provided by PowerFactory DIgSILENT is used. PowerFactory offers a built-in directly aggregation technique for the electrical system (i.e. generator, power converter, transformer, capacitor, inductance) of the wind turbine, while the mechanical part of the wind farm aggregated model, is modelled as for one individual wind turbine. The mechanical power used as input to the aggregated generator is then the mechanical output from one turbine multiplied with the number of turbines in the wind farm.

\subsection{HVDC interconnection}

The HVDC interconnection is based on two VSCs, modelled as ideal voltage sources behind reactances. Built-in converter, cable, transformer and overhead line models have been used. The transmission capacity is 160 MVA, while the voltage level is $380 \mathrm{kV}$ line-to-line on the AC side and $\pm 400 \mathrm{kV}$ on the DC link. A brief description of the VSCs' control blocks is given in the following.

\section{Onshore HVDC converter}

The onshore HVDC converter acts as DC voltage controller and is based on the control diagram depicted in Figure 3. The current references provided by the controller are then handled by a standard current controller operating in $d q$ reference frame and employing a PI block complemented by decoupling signals and voltage feed-forward - see e.g. [14]. A standard PLL based on Park's transformation is providing the angle reference.

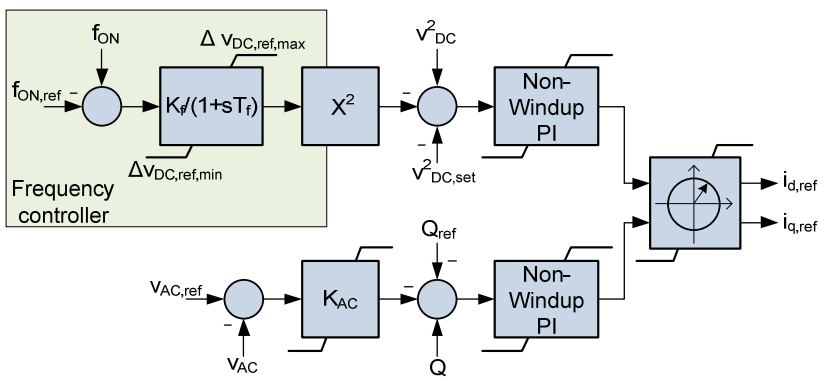

Figure 3: Onshore HVDC converter - Control block diagram.

A supplementary frequency controller has been added as outermost loop on the $d$-axis, where the DC voltage reference $\mathrm{V}_{\mathrm{DC}, \text { ref }}$ is modulated proportionally to the onshore frequency deviation. When active (i.e. with $\mathrm{K}_{\mathrm{f}} \neq 0$ ), this loop can be used in coordination with a similar control on offshore HVDC 
converter and WPP to implement the communication-less frequency control scheme (Option B).

\section{Offshore HVDC converter}

The main duty of the offshore HVDC converter is to steer the voltage magnitude and frequency at its point of connection (PoC) to the desired references. This is achieved through the use of a standard current control which references are provided by the outer controller illustrated in Figure 4.

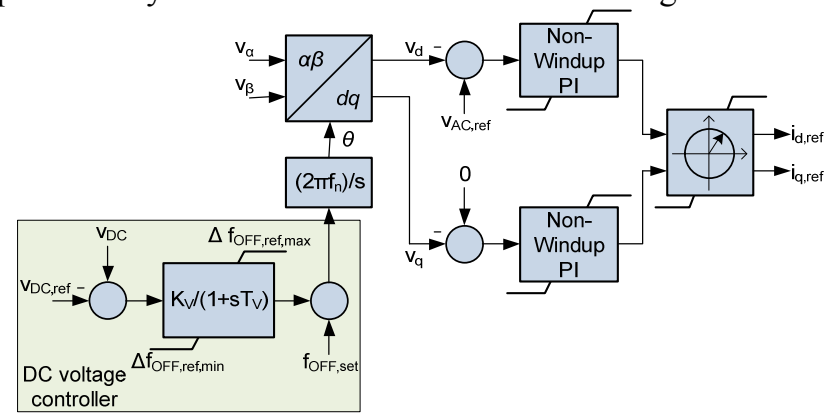

Figure 4: Offshore HVDC converter - Control block diagram.

Simply speaking, the control of $d$ - and $q$-axis voltages allows for the control of AC voltage amplitude and angle (and thus frequency) respectively. The angle reference is provided by the internal PLL, which boils down to an integrator fed by the actual frequency reference.

Analogously to what has been done on the onshore converter, a DC voltage droop controller has been added, that changes the frequency reference proportionally to the DC voltage, when activated (i.e. $\mathrm{K}_{\mathrm{V}} \neq 0$ ). This is utilised when implementing the coordinated solution (Option B).

\section{Coordinated frequency control}

As stated above, Option B allows for the implementation of a coordinated control of the frequency which transports onshore variations to the offshore network. As suggested in [11], taking the converter controllers action into account, this can be summarised by the following equqation:

$$
f_{\text {OFF }}=f_{\text {OFF,set }}+K_{V} K_{f}\left(f_{O N}-f_{O N, \text { set }}\right)+\left(R_{D C} / v_{D C}\right) P_{D C, O N}
$$

Eq. (1) is valid in steady-state and considering a $\pi$-equivalent DC cable model with neglected shunt losses. Its validity is extended to the dynamic behaviour if one considers the action of onshore DC voltage controller and offshore frequency controller to be instantaneous. Also, neglecting $\mathrm{R}_{\mathrm{DC}}$, which indeed has usually a small value, a perfect proportionality between $\mathrm{f}_{\mathrm{ON}}$ and $\mathrm{f}_{\mathrm{OFF}}$ is obtained.

\subsection{Onshore power system model}

The onshore power system has been modelled as a lumped synchronous machine with rated power 5000 MVA. Standard block diagrams and parameters for the average turbine and governing system and excitation system with AVR have been used $[15,16,17]$. The parameters of the turbine and governing system are reported in Appendix A, as they are the most relevant for the results presented in this work.

\section{Results and discussion}

Different cases were simulated in order to provide the desired comparison between diverse configurations. In the following, the scenarios will be referred to as follows:

- Option A1 - Communication based scheme with droop control: the WPP reads the onshore frequency through a communication link and provides primary frequency control.

- Option A2 - Communication based scheme with droop control and inertial contribution: like Option A1 with addition of inertial response.

- Option B1 - Coordinated scheme with droop control: the WPP reads the offshore frequency through a PLL and provides primary frequency control.

- Option B2 - Coordinated scheme with droop control and inertial contribution: like Option B1 with addition of inertial response.

The results are compared to what will be referred to as Base Case, i.e. the configuration where the WPP is insensitive to any frequency variations. Realistic parameters have been used for the internal loops according to well-known tuning techniques, while the outermost loop control parameters utilised in the Base Case and the other four configurations are reported in Appendix A. The parameters for onshore and offshore HVDC converter have been selected in order to have an offshore frequency which perfectly follows the onshore frequency in steady-state. At the same time, maximum allowed frequency deviations of $\pm 0.1 \mathrm{pu}$ are considered, corresponding to maximum allowed DC voltage deviations at $\pm 0.05 \mathrm{pu}$. The simulated event is a large positive load step on the onshore grid. Starting from an initial $2000 \mathrm{MW}$ demand, the consumption is increased by $50 \%$, creating a decreasing frequency event.

First of all, the applicability of generic WT models in a VSCHVDC connection has been demonstrated and it can be seen that their performance as for their capability of providing ancillary services is not affected by the DC decoupling - see Figures 6 and 7. Secondly, the validity of the coordinated solution adopted in Options B1 and B2 is verified. Figure 5 shows the onshore and offshore frequency for Option B1. As can be seen, an almost perfect mirroring effect is achieved. Small dynamic deviations are observed due to the interaction of DC voltage and offshore voltage controllers. A negligibly small steady-state difference is present, due to the increased voltage drop across the DC line [11]. This could easily be counteracted by gain scheduling of $\mathrm{K}_{\mathrm{V}}$ or $\mathrm{K}_{\mathrm{f}}$, if needed. Equivalently, a supplementary proportional correction targeting the onshore power can be added on the onshore converter [11]. 


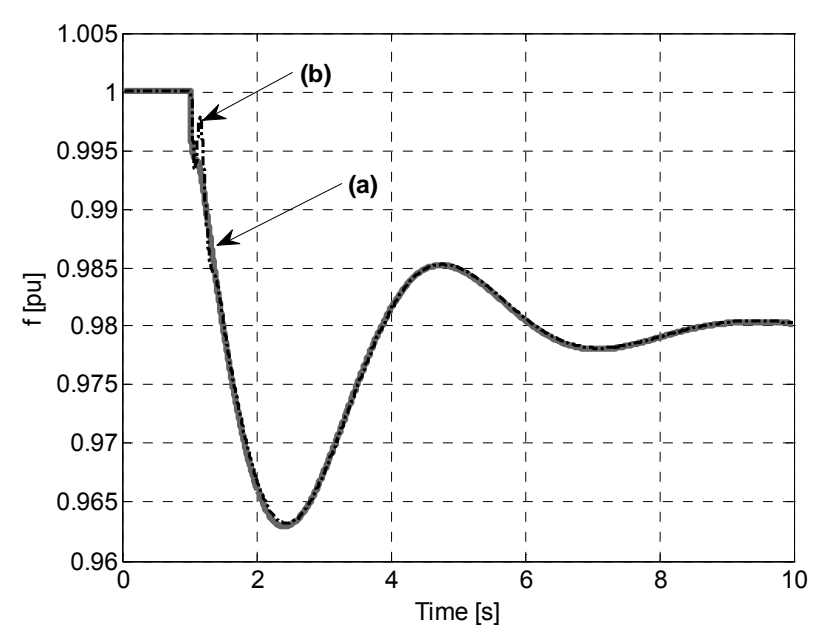

Figure 5: Option B1: (a) onshore and (b) offshore frequency.

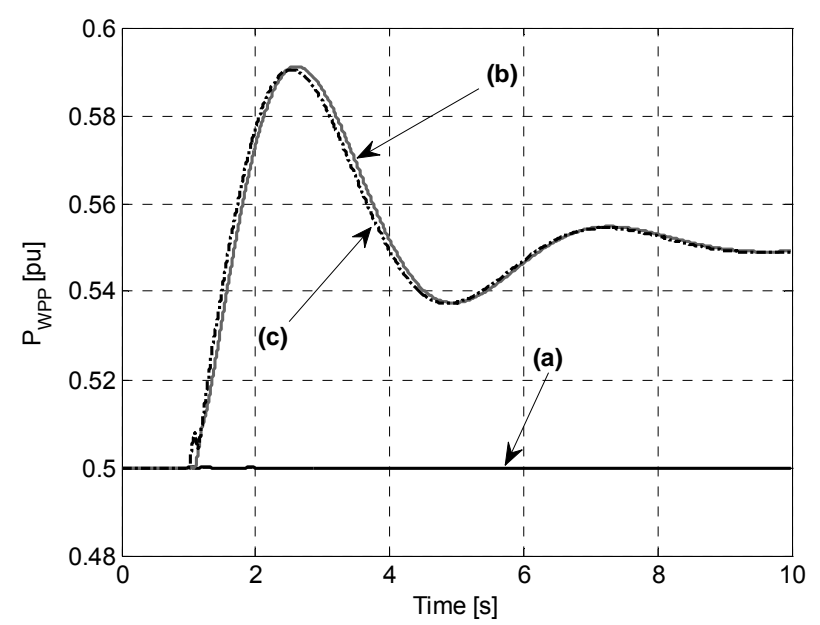

Figure 6: Wind power plant power production: (a) Base case and (b) Option A1 vs (c) Option B1.

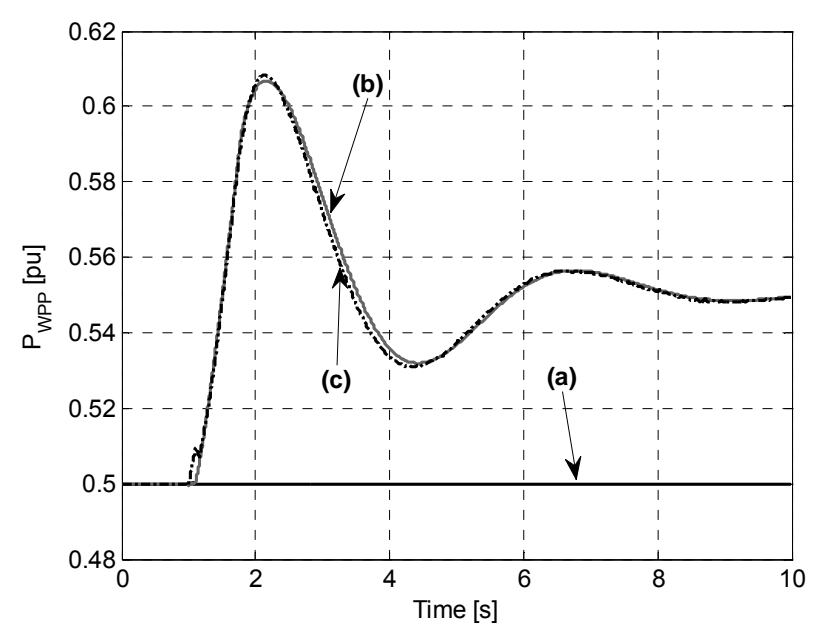

Figure 7: Wind power plant power production: (a) Base case and (b) Option A2 vs (c) Option B2.
A comparison between Options A and B is reported in Figure 6 and 7, referring to the schemes without (A1 and B1) and with (A2 and B2) inertial contribution respectively.

It can be noticed that the two solutions look basically equivalent for this case. Both communication and control coordination seem to offer the desired response from the HVDC connected WPP. However, this is subject to a number of considerations:

- The onshore AC network has been chosen to be a rather weak one. Its rotating masses possess a poor inertia and the inherent primary frequency response must therefore be reasonably fast. This means that in more realistic large grids, where dynamics are slower, the performances of Options A and B would most likely be even closer to each other.

- Part of the benefits that Options A2 and especially B2 would offer in the first instants after the event takes place are erased by the ramp rate limiter on the power controller. This issue is elucidated by Figure 8 , where the reference power for the WPP in the two Options is reported, together with its ramp-limited value. The ramp rate limit is set to $\pm 0.1 \mathrm{pu} / \mathrm{s}$, that is considered a realistic figure for modern WPPs. A possible relaxation of such limit, along with optimal settings of the control parameters, may improve the initial help from the WPP.

- The communication delay value can also slightly change the results for Option A1 and A2. The chosen figure, $100 \mathrm{~ms}$, is deemed to be realistic, but could be subject to refinement.

- As long as the disturbances' origin is a slow onshore frequency deviation, the communication delay and the ramp rate limitation, although having an influence, are not heavily affecting the performance, especially in Options A1 and B1, where the ramp rate limiter does not play any significant role. This is to a large extent true when a $\mathrm{P} 2 \mathrm{P}$ connection is concerned. However, in other configurations such as MT-HVDC, more issues may arise when disturbances directly regarding the DC voltage are of interest, since their dynamics are faster than usual onshore frequency variations.

- More aspects, going beyond the technical ones, should also be accounted for in the final evaluation of the above mentioned Options. Reliability and cost issues should therefore play an important role in the final assessment. 

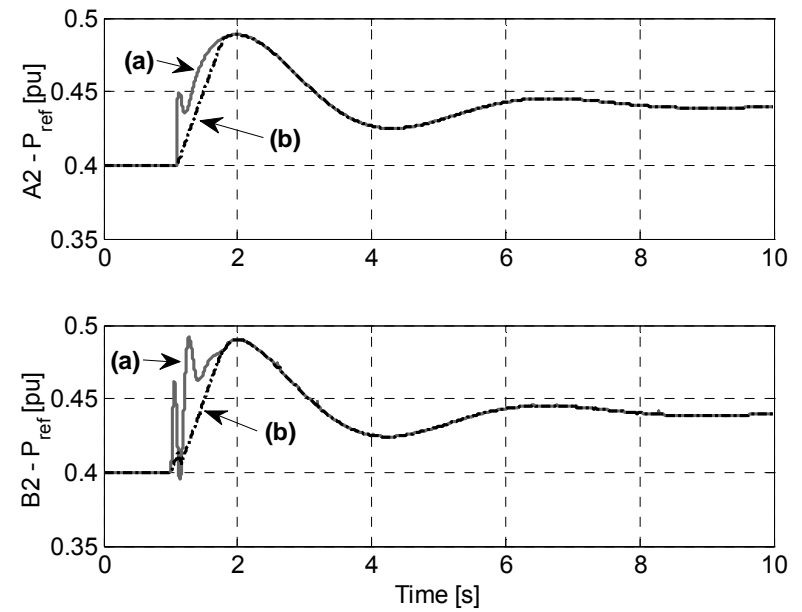

Figure 8: Wind power plant power reference in Options A2 and B2: (a) Power reference and (b) Ramp limited power reference.

\section{Conclusion and outlook}

An investigation of the applicability of generic WT models in a P2P VSC-HVDC connection has been successfully carried out, and it has been demonstrated that their capability to provide ancillary services related to disturbances on the onshore AC grid is not negatively affected by the decoupling introduced by the DC link, as long as they are accompanied by appropriate coordination means - be it communication or control.

A coordinated control aimed at mirroring onshore frequency variations on the offshore frequency has been implemented and successfully tested.

Further analysis has been proposed on a comparison between solutions employing communication and coordinated control. As long as realistic onshore frequency events are concerned, the proposed schemes offer similar performance and seem to be equivalent from a technical perspective.

Future work should be directed toward the deeper investigation of the influence of parameter setting in this configuration. Fault-handling can also be examined starting from the P2P connection. The focus should then move to the MT configuration, where faster dynamics may be involved and other issues such as handling of DC faults are still open, thus potentially changing the requirements to WPPs. Furthermore, the simple aggregation method utilised here for the WPP could be argued. The direct application of more complex WPP models will therefore be the subject of future work.

\section{Acknowledgements}

The works and developments required for the elaboration of this paper/article have been carried out partially within OffshoreDC project (www.offshoredc.dk) which belongs to the Top-level Research Initiative funded by Nordic Energy Research under project no. TFI PK-int 02.

\section{Appendix A - Control parameters}

\begin{tabular}{|l|l|l|l|l|l|}
\hline Parameter & Value & Unit & Parameter & Value & Unit \\
\hline $\mathrm{K}_{\mathrm{f}}$ & 0 & $\mathrm{pu}$ & $\mathrm{K}_{\mathrm{f}, \mathrm{WF}}$ & 0 & $\mathrm{pu}$ \\
$\mathrm{T}_{\mathrm{f}}$ & 0 & $\mathrm{~s}$ & $\mathrm{~T}_{\mathrm{f}, \mathrm{WF}}$ & 0 & $\mathrm{~s}$ \\
$\mathrm{~K}_{\mathrm{V}}$ & 0 & $\mathrm{pu}$ & $\mathrm{K}_{\mathrm{in}, \mathrm{WF}}$ & 0 & $\mathrm{pu}$ \\
$\mathrm{T}_{\mathrm{V}}$ & 0 & $\mathrm{~s}$ & $\mathrm{~T}_{\mathrm{in}, \mathrm{WF}}$ & 0.1 & $\mathrm{~s}$ \\
& & & $\mathrm{~T}_{\text {del }}$ & 0 & $\mathrm{~s}$ \\
\hline
\end{tabular}

Table A.1: Control parameters for Base Case.

\begin{tabular}{|l|l|l|l|l|l|}
\hline Parameter & Value & Unit & Parameter & Value & Unit \\
\hline $\mathrm{K}_{\mathrm{f}}$ & 0 & $\mathrm{pu}$ & $\mathrm{K}_{\mathrm{f}, \mathrm{WF}}$ & 2.5 & $\mathrm{pu}$ \\
$\mathrm{T}_{\mathrm{f}}$ & 0 & $\mathrm{~s}$ & $\mathrm{~T}_{\mathrm{f}, \mathrm{WF}}$ & 0 & $\mathrm{~s}$ \\
$\mathrm{~K}_{\mathrm{V}}$ & 0 & $\mathrm{pu}$ & $\mathrm{K}_{\mathrm{in}, \mathrm{WF}}$ & 0 & $\mathrm{pu}$ \\
$\mathrm{T}_{\mathrm{V}}$ & 0 & $\mathrm{~s}$ & $\mathrm{~T}_{\mathrm{in}, \mathrm{WF}}$ & 0.1 & $\mathrm{~s}$ \\
& & & $\mathrm{~T}_{\mathrm{del}}$ & 0.1 & $\mathrm{~s}$ \\
\hline
\end{tabular}

Table A.2: Control parameters for Option A1.

\begin{tabular}{|l|l|l|l|l|l|}
\hline Parameter & Value & Unit & Parameter & Value & Unit \\
\hline $\mathrm{K}_{\mathrm{f}}$ & 0 & $\mathrm{pu}$ & $\mathrm{K}_{\mathrm{f}, \mathrm{WF}}$ & 2.5 & $\mathrm{pu}$ \\
$\mathrm{T}_{\mathrm{f}}$ & 0 & $\mathrm{~s}$ & $\mathrm{~T}_{\mathrm{f}, \mathrm{WF}}$ & 0 & $\mathrm{~s}$ \\
$\mathrm{~K}_{\mathrm{V}}$ & 0 & $\mathrm{pu}$ & $\mathrm{K}_{\mathrm{in}, \mathrm{WF}}$ & 1.25 & $\mathrm{pu}$ \\
$\mathrm{T}_{\mathrm{V}}$ & 0 & $\mathrm{~s}$ & $\mathrm{~T}_{\mathrm{in}, \mathrm{WF}}$ & 0.1 & $\mathrm{~s}$ \\
& & & $\mathrm{~T}_{\mathrm{del}}$ & 0.1 & $\mathrm{~s}$ \\
\hline
\end{tabular}

Table A.3: Control parameters for Option A2.

\begin{tabular}{|l|l|l|l|l|l|}
\hline Parameter & Value & Unit & Parameter & Value & Unit \\
\hline $\mathrm{K}_{\mathrm{f}}$ & 0.5 & $\mathrm{pu}$ & $\mathrm{K}_{\mathrm{f}, \mathrm{WF}}$ & 2.5 & $\mathrm{pu}$ \\
$\mathrm{T}_{\mathrm{f}}$ & 0 & $\mathrm{~s}$ & $\mathrm{~T}_{\mathrm{f}, \mathrm{WF}}$ & 0 & $\mathrm{~s}$ \\
$\mathrm{~K}_{\mathrm{V}}$ & 2.0 & $\mathrm{pu}$ & $\mathrm{K}_{\mathrm{in}, \mathrm{WF}}$ & 0 & $\mathrm{pu}$ \\
$\mathrm{T}_{\mathrm{V}}$ & 0 & $\mathrm{~s}$ & $\mathrm{~T}_{\mathrm{in}, \mathrm{WF}}$ & 0.1 & $\mathrm{~s}$ \\
& & & $\mathrm{~T}_{\text {del }}$ & 0 & $\mathrm{~s}$ \\
\hline
\end{tabular}

Table A.4: Control parameters for Option B1.

\begin{tabular}{|l|l|l|l|l|l|}
\hline Parameter & Value & Unit & Parameter & Value & Unit \\
\hline $\mathrm{K}_{\mathrm{f}}$ & 0.5 & $\mathrm{pu}$ & $\mathrm{K}_{\mathrm{f}, \mathrm{WF}}$ & 2.5 & $\mathrm{pu}$ \\
$\mathrm{T}_{\mathrm{f}}$ & 0 & $\mathrm{~s}$ & $\mathrm{~T}_{\mathrm{f}, \mathrm{WF}}$ & 0 & $\mathrm{~s}$ \\
$\mathrm{~K}_{\mathrm{V}}$ & 2.0 & $\mathrm{pu}$ & $\mathrm{K}_{\mathrm{in}, \mathrm{WF}}$ & 1.25 & $\mathrm{pu}$ \\
$\mathrm{T}_{\mathrm{V}}$ & 0 & $\mathrm{~s}$ & $\mathrm{~T}_{\mathrm{in}, \mathrm{WF}}$ & 0.1 & $\mathrm{~s}$ \\
& & & $\mathrm{~T}_{\mathrm{del}}$ & 0 & $\mathrm{~s}$ \\
\hline
\end{tabular}

Table A.5: Control parameters for Option B2.

\begin{tabular}{|l|l|l|l|}
\hline Parameter & Value & Unit & \\
\hline $\mathrm{K}_{\text {sys }}$ & 10 & $\mathrm{pu}$ & System regulating energy \\
$\mathrm{T}_{\mathrm{P}}$ & 0.1 & $\mathrm{~s}$ & Governor time constant \\
$\mathrm{T}_{1}$ & 1.0 & $\mathrm{~s}$ & Turbine time constant \\
$\mathrm{H}$ & 5.0 & $\mathrm{~s}$ & Inertia constant \\
\hline
\end{tabular}

Table A.6: Parameters of turbine and governing system for equivalent onshore grid (pu on $\mathrm{S}_{\text {base }}=5 \mathrm{GVA}$ ).

\section{References}

[1] T. Ackermann, Wind Power in Power Systems, Ed. Wiley, 2005. 
[2] A.R. Ciupuliga, M. Gibescu, G. Fulli, A.L. Abbate and W.L. Kling, "Grid Connection of Large Wind Power Plants: a European Overview", 8th International Workshop on Large-Scale Integration of Wind Power into Power Systems as well as on Transmission Networks for Offshore Wind Farms, 14-15 Oct. Bremen, Germany, 2009.

[3] M. Tsili and S. Papathanassiou, "A review of grid code technical requirements for wind farms". IET Renewable Power Generation, 2009, 3, (3), pp. 308-332.

[4] A.D. Hansen and G. Michalke, "Fault ride-through capability of DFIG wind turbines", Renewable Energy 2007; 32, pp. 1594-1610.

[5] I.D. Margaris, S.A. Papathanassiou, N.D. Hatziagyriou, A.D. Hansen and P. Sørensen, "Frequency control in autonomous power systems with high wind power penetration", IEEE Transactions on Sustainable Energy, 2012, 3, (2), pp. 189-199.

[6] Windspeed, "Roadmap to the deployment of offshore wind energy in Central and Southern North Sea to 2030", final report, EU-IEE project Windspeed, March 2011. www.windspeed.eu

[7] ENTSOE, "Offshore Grid Development in the North Seas: ENTSO-E views", 2011. www.entsoe.eu

[8] N. Flourentzou, V.G. Agelidis, G.D. Demetriades, "VSC-Based HVDC Power Transmission Systems: An Overview", IEEE Transactions on Power Electronics 2009, 24, (3), pp. 592-602.

[9] L. Holdsworth, J.B. Ekanayake and N. Jenkins, "Power system frequency response from fixed speed and doubly fed induction generator-based wind turbines", Wind Energy 2004; 7: pp. 21-35. DOI:10.1002/we.105.

[10] A.D. Hansen, P. Sørensen, F. Iov and F. Blaabjerg, "Centralised power control of wind farm with doublyfed induction generators", Renewable Energy 2006; 31, pp. 935-951.

[11] Y. Phulpin, "Communication-free inertia and frequency control for wind generators connected by an HVDClink", IEEE Transactions on Power Systems 2012, 27, (2), pp. 1136-1137.

[12] IEC 61400-27 Committee Draft, Wind Turbines Part 271: Electrical simulation models for wind power generation Wind turbines, IEC Std. committee Draft (CD) 88/424/CD January 2012.

[13] I.D. Margaris, A.D. Hansen, J. Bech, B. Andersen, P. Sørensen, "Implementation of IEC Standard Models for Power System Stability Studies", $11^{\text {th }}$ Wind Integration Workshop, Lisbon, 13-15 ${ }^{\text {th }}$ November, 2012

[14] R. Teodorescu, M. Liserre, and P. Rodriguez. "Grid converters for photovoltaic and wind power systems", Wiley, 2011.

[15] A. Paolucci, "Lezioni di trasmissione dell'energia elettrica", CLEUP 2000, Padova.

[16] P. Kundur, "Power system stability and control", $4^{\text {th }}$ edition, McGraw-Hill 1994, New York.

[17] V. Akhmatov, A.H. Nielsen, "A small test model for the transmission grid with a large offshore wind farm for education and research at Technical University of
Denmark", Power Systems Conference and Exposition 2006, IEEE, pp. 650-654. 